\title{
Uma Proposta de Método de Ensino e Relatos de Experiências com a Robótica Educacional
}

\author{
Rafael Santos ${ }^{1}$, Breno Sousa ${ }^{1}$, Alberto Alan Raiol ${ }^{1}$, \\ Paulo Cerqueira ${ }^{1}$, Fábio Bezerra ${ }^{1}$
}

\author{
${ }^{1}$ Instituto Ciberespacial - Universidade Federal Rural da Amazônia (UFRA) \\ Avenida Presidente Tancredo Neves, 2501 - Belém-Pará \\ fabio.bezerra@ufra.edu.br
}

\begin{abstract}
This paper presents the EDATM method of teaching. This method aggregate exercises $(E)$, dynamics $(D)$ and play activities, lessons $(A)$, evaluations through tests $(T)$ and missions or challenges $(M)$. The method assists the teacher in his pedagogical activities, guiding you to review contents, present new contents in a more fun way and measure the learning of his students with tests and challenges. Two different contexts of evaluation of the method are presented in the paper: elementary school students and higher education entrants. The results of self-evaluation of the student's feeling in the elementary school classes showed positive levels for satisfaction, motivation, and control. The method was also evaluated by the students of higher education, satisfying the expectation in the learning of programming concepts.
\end{abstract}

Resumo. Este trabalho apresenta o método EDATM de ensino. Este método congrega exercícios (E), dinâmicas (D) e atividades lúdicas, aulas (A), avaliações através de teste (T) e missões ou desafios (M). O método auxilia o professor em suas atividades pedagógicas, orientando-o a revisar conteúdos, apresentar novos conteúdos de forma mais divertida e medir a aprendizagem de seus alunos com testes e desafios. Dois contextos diferentes de avaliação do método são apresentados no trabalho: alunos do ensino fundamental e ingressantes do ensino superior. Os resultados da autoavaliação do sentimento do aluno nas turmas do ensino fundamental demonstraram níveis positivos para satisfação, motivação e controle. O método também foi avaliado pelos discentes do ensino superior, satisfazendo a expectativa no aprendizado de conceitos de programação.

\section{Introdução}

A Sociedade Brasileira de Computação (SBC) lançou em 2018 um manifesto ${ }^{1}$ em favor da inserção da computação na educação básica. Segundo este documento, o ensino de computação nas séries iniciais poderá assegurar que a população alcance melhores níveis de qualidade de vida, além disso, considera que possuir conhecimentos em computação na atualidade é tão importante quanto a alfabetização no passado.

Diante do contexto da aprendizagem na atualidade, com propósitos mais amplos de desenvolvimento do indivíduo, novas políticas são propostas, prova disso, são

\footnotetext{
${ }^{1}$ Disponível em: https://bit.1y/2LTWvI7
} 
as mudanças na Base Nacional Comum Curricular (BNCC) para educação básica, que das 10 competências gerais elaboradas, a $5^{\text {a }}$ objetiva a apropriação do tema "cultura digital" pelo aluno, para o uso qualificado e ético das ferramentas digitais e também o desenvolvimento do Pensamento Computacional (PC).

Para [de Sá and Mendes 2018], o Brasil deve tratar sobre a inserção e efetivação do uso das Tecnologias de Informação e Comunicação (TIC) nas escolas públicas como assunto de fundamental importância, pois o tema trata de uma política estratégica e está relacionado ao desenvolvimento econômico, científico e social do país. No entanto, além da importante discussão sobre quais conteúdos de TIC incluir na educação básica, também é fundamental discutir métodos e estratégias de ensino desses conteúdos a esse público.

Visando contribuir com às discussões relacionadas as estratégias de ensino de conteúdos de informática, este trabalho apresenta relatos de experiências de oficinas de Programação com Robótica Educacional com alunos de uma escola pública e com ingressantes do ensino superior (ver Seção 5). No caso, este trabalho apresenta um método que reforça no professor uma apresentação lúdica de conteúdos, combinada com avaliações continuadas desses conteúdos (Seção 3).

Com o intuito de avaliar o método, um plano de ensino de uma oficina, que contemplou dez aulas foi elaborado (Seção 4). Então, duas experiências são relatadas. A primeira, na escola pública, ocorreu no contraturno, com um encontro semanal, e envolveu duas turmas. A segunda, com os calouros, ocorreu em uma versão reduzida da primeira, por ter sido executada em dois dias, durante a semana de recepção dos calouros.

A investigação se junta aos debates, uma vez que as experiências ocorreram em dois contextos. Mostraram-se relevantes no ensino de programação tanto no ensino básico quanto no ensino superior, e o método proposto contribuiu como fator motivacional para o debate da cultura digital.

\section{Trabalhos Relacionados}

Diversas pesquisas foram realizadas a fim de testar e consolidar práticas pedagógicas adequadas a educação em computação na educação básica e superior, como em: [Mattos et al. 2015, Ferreira et al. 2016, Souza and Castro 2016, Reinaldo et al. 2016].

\subsection{Ensino de Programação de Computadores}

Em [Mattos et al. 2015] os autores relatam a aplicação do projeto de extensão chamado "Lego nas Escolas", que uniu programação e robótica como meio para explorar a resolução de problemas. Para essa experiência, foi utilizado o Kit Educativo LEGO $^{\circledR}$ Mindstorms, que possui o software de programação com interface atrativa e de fácil aprendizagem.

Em [Ferreira et al. 2016] os autores expõem a experiência de ensino de conceitos básicos de programação de computadores, ofertado à comunidades de Salvador e região metropolitana, dirigido ao público jovem e adulto sem familiaridade com programação. O trabalho de extensão teve como objetivo despertar o raciocínio lógico e computacional, a criatividade e estimular o interesse de alunos pela área de computação, através de atividades desplugadas baseadas na metodologia de ensino proposta por [Bell et al. 2011] e intitulada "Computer Science Unplugged", além dos softwares Scratch e VisuAlg. 
A fim de minimizar as dificuldades de aprendizado em programação por estudantes da educação básica, no trabalho de [Souza and Castro 2016], por meio de uma Revisão Sistemática de Literatura (RLS), analisou-se pesquisas nacionais e internacionais publicadas entre os anos de 2009 e 2016 que utilizaram a ferramenta Scratch para o ensino de programação com crianças. Notou-se a dificuldade com a difusão da cultura do ensino de programação no país, sendo a baixa infraestrutura e a falta de treinamento para professores os principais fatores. Apesar disso, o Scratch tem sido uma linguagem de programação bastante utilizada no ensino fundamental.

Considerando as dificuldades de ensino-aprendizado nos cursos superiores em disciplinas de programação, [Reinaldo et al. 2016] apresenta o desenvolvimento de um Objeto de Aprendizagem (OA) no formato de um kit didático com plataformas abertas de software e hardware, e teve como objetivo proporcionar ao aluno o primeiro contato com os conceitos que são ensinados nas disciplinas de algoritmos e lógica de programação de forma lúdica.

Nos trabalhos apresentados acima visualizou-se algumas maneiras de introduzir os conceitos de programação através de ferramentas e metodologias distintas. Neste trabalho, o método apresentado foi aplicado em dois contextos educacionais, e utilizou a robótica educacional como ferramenta de ensino de conceitos básicos de programação de forma interativa e divertida.

\subsection{Robótica Educacional}

Robótica Educacional (RE) pode ser entendida como um termo amplo, no entanto, para [Castro 2008, p. 27], ela "pode ser definida como a implementação de dispositivos interfaceáveis com o computador com finalidades educacionais"; [Chella 2002, p. 23], complementa que, a RE é um ambiente no qual os alunos se envolvem com diferentes componentes, programam dispositivos automatizados tendo em vista conceitos de diversas áreas do conhecimento. A RE se apresenta nas áreas de ciência, tecnologia, engenharias e matemática (STEM - do inglês Science,Technology, Engineering, and Mathematics) [de Aguiar and Lunardi 2015].

No trabalho de [Zilli 2004] a RE é analisada como recurso pedagógico das perspectivas em relação ao processo cognitivo dos alunos, em instituições públicas e privadas de Curitiba-PR. Na experiência analisou-se as escolas que utilizaram a RE como recurso no Ensino Fundamental, de $5^{\mathrm{a}}$ a $8^{\mathrm{a}}$ séries. Em [de Silva et al. 2008], o trabalho é baseado no enfoque sócio histórico para amenizar a exclusão digital em uma escola localizada na periferia de Natal, a fim de fomentar a aprendizagem colaborativa com alunos do $4^{\circ}$ e $5^{\circ}$ anos que apresentavam dificuldades. Observou-se que os alunos melhoraram no aspecto de trabalho em grupo e na construção do próprio conhecimento.

Buscando contribuir para o aumento do interesse pelos cursos na área de TI, [Andrade et al. 2016] utilizou a ferramenta Scratch com estudantes do $1^{\circ}$ e $2^{\circ}$ anos do ensino médio de uma escola pública do município de Mamanguape-PB, para explorar conceitos da computação e estimular a criatividade na criação de jogos. Observou-se que o processo de desenvolvimento de jogos digitais pode contribuir como fator motivacional no processo e ensino-aprendizagem.

Semelhante aos relatos acima citados, este trabalho apresenta um método para o ensino de conceitos de programação, sendo desenvolvido com auxílio da robótica educaci- 
onal, onde foi aplicada a programação com blocos e utilização do Kit Lego Mindstorms.

\section{Método de Ensino EDATM}

Nesta seção apresentamos o Método de Ensino EDATM, um acrônimo das cinco etapas que o definem: Exercício, Dinâmica, Aula, Teste e Missão. O método tem uma estrutura organizacional, ou seja, etapas que possuem uma significância pedagógica. No primeiro encontro é explorado o DAT (Dinâmica, Aula e Teste), e a partir do segundo encontro, todas as cinco etapas são abordadas, em razão de iniciar-se a revisão da aula anterior.

As etapas estão associadas aos principais elementos do Pensamento Computacional: (i) Decomposição de um problema complexo em partes menores e mais gerenciáveis; (ii) Reconhecimento de padrões e semelhanças nos problemas; (iii) Abstração e atenção apenas nas informações importantes; (iv) Algoritmos da solução do problema, ou as regras ou instruções que uma máquina deve seguir para resolver o problema [Wing 2016].

\subsection{Exercício}

A consolidação é entendida como um tipo de aula na qual tem como característica principal proporcionar exercícios de recordação, além de sistematização e aplicação. À vista disso, se propõe rever o que foi trabalhado nas aulas passadas, ou melhor, revisar um conteúdo já trabalhado, possibilitando ao aluno a chance de prosseguir para novos conhecimentos, uma vez que o anterior tenha sido solidificado [Libâneo 2017, p. 211]. Para gerar confiança na abordagem de novos conteúdos, esta etapa é pautada na revisão de assuntos trabalhados em aulas anteriores.

Quanto a relação da etapa Exercício com o PC, há um elemento em comum entre eles, a decomposição de problemas. Nesta etapa do Método, a decomposição de problemas é vista na ação de relembrar e solidificar a tarefa trabalhada anteriormente. Tal ação divide o aprendizado de um conceito em etapas e facilita seu entendimento, uma vez que o aluno apresente dificuldades de assimilar o conteúdo no primeiro contato, ele terá a oportunidade de dividir a assimilação de conhecimento em partes. Logo, a etapa Exercício é importante porque visa amadurecer a compreensão dos conteúdos vistos antes.

\subsection{Dinâmica}

A Dinâmica é um momento para abordagem prática do conceito que será trabalhado na aula do dia. O objetivo é introduzir o conceito teórico da aula com uma atividade individual ou coletiva, para que todos se envolvam e percebam o significado da proposta deste momento prático da aula. Esta atividade tem caráter lúdico e por vezes de competição. Algo semelhante ao que ocorre em [Bell et al. 2011], onde os autores trabalham uma proposta "desplugada" para ensinar conceitos fundamentais da Ciência da Computação sem o uso do computador.

Uma das propostas da Dinâmica é possibilitar a compreensão do conteúdo de forma mais fácil. Dessa forma, sua relação com os elementos do Pensamento Computacional se dá com a Abstração, ou seja, a resolução do problema tem o enfoque nos pontos mais importantes.

\subsection{Aula}

Na etapa Aula, o objetivo é inserir o assunto novo. Para que o debate não seja iniciado apenas de forma expositiva pelo professor, o conceito é associado aos trabalhos desen- 
volvidos na Dinâmica, também com exemplos do cotidiano. Assim, a aula decorre na perspectiva da aula dialogada, onde há uma interação e contribuição ativa entre professor e aluno visando a obtenção de novos conhecimentos [Libâneo 2017, p. 184, 185].

É possível considerar, então, que um conceito visto como complexo pode se tornar mais fácil de ser compreendido, pois, a etapa Aula está diretamente associada a Dinâmica. Para mais, há uma relação com o elemento abstração do Pensamento Computacional, na forma de abordagem do novo conceito, que se utiliza na Dinâmica mais exemplos do dia a dia, ou seja, é apresentado um conceito, sem o enfoque em detalhes, após, sucedesse o debate em grupo.

\subsection{Teste}

O Teste é um momento para o aluno praticar os desafios semelhantes aos que serão apresentados posteriormente em uma missão, podendo neste estágio recorrer ao professor para sanar suas dúvidas, assim, é uma fase de preparação onde o aluno poderá elaborar suas próprias hipóteses a respeito da melhor maneira de construção, programação do robô e solução do desafio apresentado. O teste proporciona reforço do aprendizado, em concordância, [Libâneo 2017] considera uma aula de consolidação quando a mesma possui os conceitos exercícios, recordação, sistematização e aplicação.

Quanto a esta etapa, relaciona-se com o PC nos seguintes pontos: decomposição, em razão de que o aluno se organiza em passos menores e gradativos durante os exercícios propostos, e (ii) algoritmo que é a estrutura base para a solução do problema, onde há uma ordenação da sequência de passos antes da ação a ser executada.

\subsection{Missão}

A etapa Missão, tem um carácter avaliativo. Sendo assim, após as fases de introdução e aprofundamento do conteúdo, bem como de Teste para exercitar na prática os desafios apresentados, a Missão possui um nível de complexidade maior, logo, é realizada pela equipe sem o auxílio do professor. O desempenho do aluno será avaliado de acordo com critérios preestabelecidos, tais como: i) organização e método e ii) cumprimento da missão.

Por fim, a correspondência desta etapa com o PC é vista nos mesmos elementos citados no Teste, contudo, tanto a criação de regras quanto a divisão do desafio em partes menores para tornar a resolução mais simples, tornam-se mais exigidas, uma vez que o comportamento autônomo é fator importante para o cumprimento do desafio.

\section{Plano de Ensino}

O plano de ensino tem carga horária total de 30 horas contemplando dez aulas de três horas. Todas as aulas foram norteados pelo método EDATM. Dentre os principais tópicos no contexto de programação de computadores foi trabalhado o princípio das três estruturas básicas (Sequência, Seleção e Repetição), explorando algoritmo, lógica de programação, programação com sequência, programação com decisão e programação com laço. Cada aula foi nomeada com um termo cotidiano associado ao conteúdo.

Na tabela abaixo, encontra-se o conteúdo programático do curso. 
Tabela 1. Planejamento Resumido da Oficina

\begin{tabular}{|c|c|c|}
\hline Aula & Conteúdo & Desenvolvimento \\
\hline 1- Hello World & $\begin{array}{l}\text { Conceitos iniciais de computação e } \\
\text { robótica; Aula exploratória do kit } \\
\text { LEGOß MINDSTORMS Educa- } \\
\text { tion EV3. }\end{array}$ & $\begin{array}{l}\text { Compreender conceitos iniciais de: } \\
\text { - computação - robótica - conhe- } \\
\text { cer o kit LEGO@ MINDSTORMS } \\
\text { EV3. }\end{array}$ \\
\hline 2- Hello World 2.0 & $\begin{array}{l}\text { Algoritmo, Lógica e Pensamento } \\
\text { Computacional. }\end{array}$ & $\begin{array}{l}\text { Compreender o conceito de lógica } \\
\text { de programação através de ativida- } \\
\text { des práticas. }\end{array}$ \\
\hline 3-Compilando & Entrada e Saída de Dados. & $\begin{array}{l}\text { Entender as três etapas que } \\
\text { compõem o ciclo de processamento } \\
\text { de dados. }\end{array}$ \\
\hline 4- Você Pode Repetir? & $\begin{array}{l}\text { Repetição: Ciclo, interruptor de ci- } \\
\text { clo. }\end{array}$ & $\begin{array}{l}\text { Desenvolver e aplicar conceitos de } \\
\text { repetição, utilizando os blocos de } \\
\text { controle de ciclo. }\end{array}$ \\
\hline 5- Jogando os Dados & $\begin{array}{llll}\text { Variáveis } & \text { e } & \text { operadores ma- } \\
\text { temáticos. } & & & \\
& & \end{array}$ & $\begin{array}{l}\text { Entender o conceito de variáveis, os } \\
\text { tipos e conversão de variáveis, utili- } \\
\text { zando os operadores matemática no } \\
\text { EV3; }\end{array}$ \\
\hline 6- Fantoche & Seleção. & $\begin{array}{l}\text { Entender o conceito da estrutura } \\
\text { condicional "SE" }\end{array}$ \\
\hline 7- Fantoche 2.0 & Seleção. & $\begin{array}{l}\text { Entender o conceito da estrutura } \\
\text { condicional "SE - SENÂO" }\end{array}$ \\
\hline 8 - Verdadeiro ou Falso & $\begin{array}{l}\text { Operadores lógicos; Operadores } \\
\text { de comparação; Programação com } \\
\text { operadores lógicos. }\end{array}$ & $\begin{array}{l}\text { Conhecer operações lógicas na } \\
\text { programação; Conhecer os tipos de } \\
\text { operadores lógicos; Aplicar con- } \\
\text { ceito. }\end{array}$ \\
\hline 9 - Replay & $\begin{array}{l}\text { Algoritmo, PC, Lógica, Repetição, } \\
\text { Variável, Seleção. }\end{array}$ & Revisar conteúdos estudados \\
\hline 10 - Missões & Socialização dos conhecimentos. & $\begin{array}{l}\text { Apresentar projetos e soluções de- } \\
\text { senvolvidas para a comunidade es- } \\
\text { colar e familiares. }\end{array}$ \\
\hline
\end{tabular}

\section{Experiências de Aplicação do Método de Ensino EDATM}

Com uma abordagem qualitativa, de natureza exploratória, duas experiências de aplicação do método de ensino EDATM serão relatadas. A primeira, na Escola Estadual de Ensino Fundamento e Médio Barão de Igarapé Miri, realizada no primeiro semestre de 2018 e a segunda, durante a semana de recepção dos calouros 2018.1 da Universidade Federal Rural da Amazônia (UFRA).

\subsection{Escola Estadual de Ensino Fundamento e Médio Barão de Igarapé Miri}

A escola Barão de Igarapé Miri é uma das 1.023 escolas localizadas em Belém, capital do Pará ${ }^{2}$. Em Belém nos anos iniciais e finais do ensino fundamental da rede pública, o Ideb cresce desde 2005, mas não atingiu a meta e não alcançou nota 6,0 até $2015^{3}$. Sobre o Ideb da escola, a classificação é de Alerta, o que significa que a escola não aumentou seu Ideb e não atingiu sua meta, que está abaixo de 6.0.

Neste cenário, dedicamos especial atenção para as turmas iniciais do ensino fundamental II (6- e 7o ano). Tendo como objetivo identificar em qual destas turmas a proposta

\footnotetext{
${ }^{2}$ Dados disponíveis emhttp://www. qedu.org.br/busca/114-para/3173-belem

${ }^{3}$ Dados disponíveis emhttps://goo.gl/eW3sMt
} 
do plano de ensino com o método EDATM, teria melhor aceitação e engajamento dos alunos. As aulas ocorreram uma vez por semana, sendo na segunda-feira a aula com o $6^{0}$, e na quarta-feira com o 7ㅇ․

As atividades foram realizadas no primeiro semestre de 2018, totalizaram uma carga horária de 21 horas, dividida em 7 aulas de 3 horas, ocorridas no contraturno, com início as 8:30 e encerramento as 11:30 da manhã. O horário considerou o tempo gasto pelos alunos para deslocamento tanto de ida para a oficina quanto de volta para a suas casas. Foi considerado conveniente ofertar 15 vagas para cada turma, por estar adequado ao número de kits de Robótica disponíveis para a experiência de ensino, obtendo no total 30 alunos matriculados no curso.

Duas semanas antes do início das atividades, a oficina foi divulgada em seu contexto geral nas turmas, com oportuna demonstração de um Robô construído de peças LEGO $\cap$ em funcionamento. Considerando as observações da coordenadora pedagógica da escola, o curso foi divulgado nas turmas do vespertino para frequentarem as aulas no matutino. Para os interessados foi entregue uma ficha de inscrição com uma breve descrição do curso e o calendário das aulas, e como exigência de participação no curso um responsável pelo aluno precisava ler e assinar a ficha de inscrição.

Turma 1 (Sexto ano): A turma formada pelos alunos do 6o foi a que mais houve adesão de matriculados em relação as demais. Ao todo, 12 alunos se matricularam no curso, destes, sete meninos e cinco meninas com idades entre 10 a 12 anos.

Iniciando as atividades, dez alunos compareceram no primeiro dia de aula, formando quatro equipes. Os alunos foram orientados a dar um nome para a equipe, os resultados foram: Robô Fashion, Roboticando, Robô Hero e Robô Game. Oito alunos permaneceram até a última aula do curso. Após ter sido ministrada sete das dez aulas previstas, ocorreu uma greve dos professores da rede estadual por tempo indeterminado, fato que impossibilitou a continuidade das aulas, por esse motivo as atividades foram encerradas.

Turma 2 (Sétimo ano): Na turma do 7ํano, houve 8 alunos matriculados, sendo seis meninos e duas meninas com idade entre 11 a 13 anos. Por este período, havia uma média de 240 alunos matriculados nas turmas de $7^{\circ}$ ano, sendo três turmas no matutino e três turmas no vespertino. Nesta turma, três grupos foram formados com os seguintes nomes, Dragon Ball, Robustos e Megatron. No decorrer das aulas um ou outro aluno esteve ausente em uma ou outra aula, porém, iniciamos a turma com cinco alunos e encerramos com seis alunos.

\subsection{Semana do Calouro na UFRA}

A semana do calouro da UFRA é um evento que oferece uma acolhida dos novos alunos e socialização desses calouros com os veteranos. Essa semana também apresenta a administração e rotina da Universidade, além de informações gerais sobre o curso que o aluno foi admitido.

Esta experiência da oficina de programação com Robótica Educacional ocorreu em uma versão reduzida no âmbito do ensino superior, com calouros. Na oficina de Robótica, foram ministradas quatro das dez aulas presentes no plano de curso, em seis horas de oficina, três horas no primeiro dia e as três restantes no dia seguinte. O conteúdo 
de cada dia foi estruturado em dois momentos, cada um dedicado ao ensino de um novo conceito. Para tanto, a oficina foi organizada com o seguinte conteúdo: conceitos de algoritmo, de lógica, de pensamento computacional, de entrada e saída de dados e conceitos de estruturas de repetição e seleção em um algoritmo. Os conteúdos foram organizados em quatro partes, sendo i) Hello World e ii) Compilando, no primeiro dia; e iii) Você pode repetir? e iv) Fantoche, no segundo dia.

\section{Resultados e Discussões}

O ensino de programação de computadores na educação básica pode favorecer o estudante com o desenvolvimento do raciocínio lógico, da capacidade de resolução de problemas, do estímulo ao trabalho em equipe, sendo todas essas habilidades importantes para a vida escolar. No entanto, os procedimentos de ensino tradicionais podem desestimular o estudo pelo estudo de programação.

O desenvolvimento desta pesquisa possibilitou uma análise de como o método de ensino EDATM ajudou no aprendizado de programação, empregando a Robótica Educacional como ferramenta pedagógica, nos contextos de uma escola pública de ensino básico, com 20 alunos, e no ensino superior, com 15 calouros de dois cursos de área de informática. Possibilitando uma nova proposta de ensino-aprendizagem de conteúdos da computação.

\subsection{Resultados}

Os resultados foram coletados a partir do método $S A M$, um formulário não verbal que expressa a visão pessoal e emocional do aluno sobre a oficina em três sentimentos, Satisfação, Motivação e Controle. Para a primeira experiência na escola pública, os resultados coletados apresentam o sexto ano, com respostas dos alunos indicando 95\% para satisfação, $75 \%$ para motivação e $70.5 \%$ para controle.

Os resultados coletados na turma do sétimo ano também forma bastantes expressivos. De um total de 40 respostas obtidas em seis aulas, $90 \%$ dos pareceres dos alunos sinalizaram estarem satisfeitos, houve um apontamento de $80 \%$ para o nível de motivação e $72,5 \%$ para os registro do sentimento de controle.

Na segunda experiência, no contexto do ensino superior, duas avaliações foram aplicadas: (i) método $S A M$; (ii) avaliação da oficina pelo aluno. Quanto a auto-avaliação do sentimento do aluno, as respostas foram coletadas e atribuídas a votos positivos ( $\mathrm{V}+$ ), negativos (V-) e votos neutros (VN). No caso, a satisfação e motivação foram predominantemente positivas obtendo $100 \%$, enquanto que para o controle $73 \%$ de respostas positivas.

\subsection{Discussões}

Nesse sentido, o método de ensino proposto tornou o aprendizado de conceitos de programação e pensamento computacional mais atrativo, pois proporciona o primeiro contato com conceitos de computação de forma lúdica (dinâmicas em grupo) antes da abordagem teórica, fato convergente com os resultados expressivos na autoavaliação SAM sobre o sentimento do aluno na aula. Para os dados da escola pública a média dos níveis positivos de satisfação, motivação e controle dos três campos alcançaram respectivamente $92,5 \%, 77,5 \%$ e $71,5 \%$. 


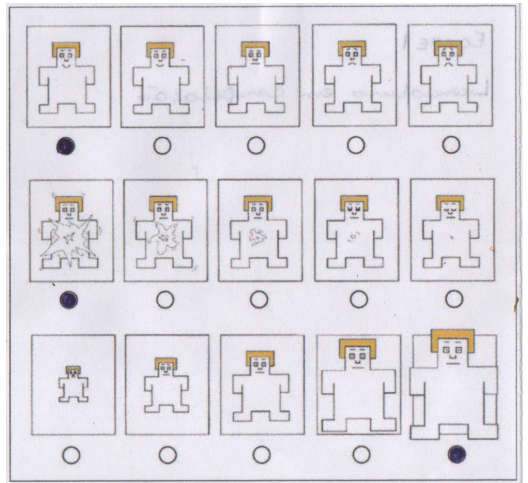

(a) Auto-avaliação do sentimento do aluno.

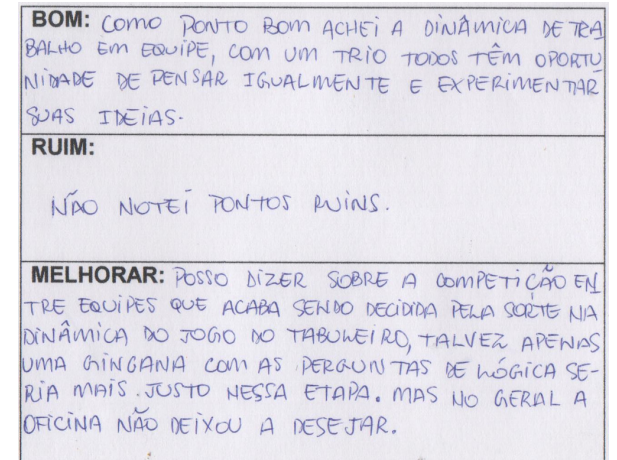

(b) Avaliação da oficina pelo aluno.

Figura 1. Avaliações do aluno

Para mais, também foi evidenciado que na experiência com os alunos recémchegados na Universidade, por meio de uma avaliação com três conceitos (BOM, RUIM, MELHORAR), respondida no final dos dois dias, avaliaram a oficina com o conceito BOM e destacaram a didática como fator que favoreceu o aprendizado dos conceitos de programação, como mostrado na figura 1 .

Sendo assim, método de ensino EDATM se mostrou apropriado como instrumento educacional para ajudar na compreensão de conceitos de programação por estudantes do ensino fundamental, e como meio estimulante de apresentação dos estudantes com conteúdos introdutórios dos cursos superiores da área de informática, especialmente, Licenciatura em Computação e Bacharelado em Sistemas de Informação, nos quais foram um dos públicos desta pesquisa acadêmica.

\section{Considerações Finais}

Este artigo apresentou o Método EDATM, bem com as experiências de aplicação do método, no ensino de programação de computadores no ensino fundamental e superior. O objetivo do método é possibilitar o ensino de conceitos de programação de maneira lúdica, sendo um atividade atrativa para o estudante.

Nesse sentido, o trabalho considerou como resultado, a auto-avaliação do sentimento do aluno (SAM) e a avaliação da oficina realizada por eles. Os resultados obtidos nas perspectivas de avaliação foram positivos e mostraram que o método utilizado no ensino de computação pode ser um fator primordial no aprendizado e na motivação do aluno. Portanto, o Método pode contribuir para o desenvolvimento do Pensamento Computacional, bem como para o ensino de programação de computadores, pois favorece uma abordagem prática e gradativa dos conceitos.

Como futuras ações a serem desenvolvidas, pretende-se avaliar os impactos do método EDATM no desempenho escolar, como exemplo, o desempenho do aluno na disciplina de matemática. No contexto do nível superior, planeja-se examinar o rendimento nas disciplinas de lógica e programação. Além disso, analisar de modo sistemático os dados coletados desta pesquisa. 


\section{Referências}

Andrade, R., Mendonça, J., Oliveira, W., Araujo, A. L., and Souza, F. (2016). Uma proposta de oficina de desenvolvimento de jogos digitais para ensino de programação. In Anais dos Workshops do Congresso Brasileiro de Informática na Educação, volume 5, page 1127.

Bell, T., Witten, I. H., and Fellows, M. (2011). Computer science unplugged. ensinando ciência da computação sem o uso do computador. Tradução coordenada por Luciano Porto Barreto.

Castro, V. G. d. (2008). Roboeduc: especificação de um software educacional para ensino da robótica às crianças como uma ferramenta de inclusão digital. Master's thesis, Universidade Federal do Rio Grande do Norte, Natal, RN. Online; accessed 21-Junho2018.

Chella, M. T. (2002). Ambiente de robótica para aplicações educacionais com superlogo. mathesis, UNICAMP, Campinas, SP.

de Aguiar, A. F. and Lunardi, R. C. (2015). Aplicação da robótica como instrumento de ensino através de competições. Semex em Resumos, 3(3).

de Sá, R. A. and Mendes, A. A. P. (2018). Entrevista: As tecnologias da informação e comunicação nas escolas de educação básica. REVISTA INTERSABERES, 12(27):495499.

de Silva, A. F., Silva, A., Gonçalves, L. M. G., Guerreiro, A. M. G., and Barrios-Aranibar, D. (2008). Utilização da teoria de vygotsky em robótica educativa, em '. In CaracasVenezuela. Congreso Iberoamericano de Informatica Educativa RIBIE 2008.

Ferreira, A. C., Santos, J., Silva, R., Oliveira, A. T. R., Zabot, D., Abdalla, D., and Matos, E. (2016). Hello world: relato de experiência de um curso de iniciação à programação. In Anais dos Workshops do Congresso Brasileiro de Informática na Educação, volume 5, page 1306.

Libâneo, J. C. (2017). didática. Cortez Editora, São Paulo.

Mattos, S. D. G., de Oliveira, V. M., Soares, L. B., de Aguiar, Y. Q., and Maciel, B. K. (2015). Introdução à robótica e estímulo à lógica de programação no ensino básico utilizando o kit educativo lego $囚$ mindstorms. In Anais dos Workshops do Congresso Brasileiro de Informática na Educação, volume 4, page 1418.

Reinaldo, B., Bampi, M., and Sampaio, F. (2016). Kit-log: Objeto de aprendizagem para auxílio no processo de ensino-aprendizagem de lógica de programação. In Anais dos Workshops do Congresso Brasileiro de Informática na Educação, volume 5, page 403.

Souza, S. and Castro, T. (2016). Investigação em programação com scratch para crianças: uma revisão sistemática da literatura. In Anais dos Workshops do Congresso Brasileiro de Informática na Educação, volume 5, page 1078.

Wing, J. (2016). Pensamento computacional-um conjunto de atitudes e habilidades que todos, não só cientistas da computação, ficaram ansiosos para aprender e usar. Revista Brasileira de Ensino de Ciência e Tecnologia, 9.

Zilli, S. d. R. (2004). A robótica educacional no ensino fundamental: perspectivas e prática. Master's thesis, UFSC. Online; accessed 20-Junho-2018. 